\title{
Quantifying the economic cost of antibiotic resistance and the impact of related interventions: rapid methodological review, conceptual framework and recommendations for future studies
}

\author{
Mark Jit ${ }^{1,2,3^{*}}$, Dorothy Hui Lin $\mathrm{Ng}^{4}$, Nantasit Luangasanatip ${ }^{1,5}$, Frank Sandmann ${ }^{1,2}$, Katherine E. Atkins ${ }^{1,6}$,
} Julie V. Robotham ${ }^{2,7,8}$ and Koen B. Pouwels $2,7,9$

\begin{abstract}
Background: Antibiotic resistance (ABR) poses a major threat to health and economic wellbeing worldwide. Reducing ABR will require government interventions to incentivise antibiotic development, prudent antibiotic use, infection control and deployment of partial substitutes such as rapid diagnostics and vaccines. The scale of such interventions needs to be calibrated to accurate and comprehensive estimates of the economic cost of ABR.

Methods: A conceptual framework for estimating costs attributable to ABR was developed based on previous literature highlighting methodological shortcomings in the field and additional deductive epidemiological and economic reasoning. The framework was supplemented by a rapid methodological review.

Results: The review identified 110 articles quantifying ABR costs. Most were based in high-income countries only (91/110), set in hospitals (95/110), used a healthcare provider or payer perspective (97/110), and used matched cohort approaches to compare costs of patients with antibiotic-resistant infections and antibiotic-susceptible infections (or no infection) (87/110). Better use of methods to correct biases and confounding when making this comparison is needed. Findings also need to be extended beyond their limitations in (1) time (projecting present costs into the future), (2) perspective (from the healthcare sector to entire societies and economies), (3) scope (from individuals to communities and ecosystems), and (4) space (from single sites to countries and the world). Analyses of the impact of interventions need to be extended to examine the impact of the intervention on $A B R$, rather than considering $\mathrm{ABR}$ as an exogeneous factor.
\end{abstract}

Conclusions: Quantifying the economic cost of resistance will require greater rigour and innovation in the use of existing methods to design studies that accurately collect relevant outcomes and further research into new techniques for capturing broader economic outcomes.

Keywords: Antimicrobial resistance, Antibiotics, Economic costs, Economic evaluation

\footnotetext{
* Correspondence: mark.jit@lshtm.ac.uk

'The National Institute for Health Research (NIHR) Health Protection Research

Unit in Immunisation, London School of Hygiene \& Tropical Medicine,

Keppel Street, London WC1E 7HT, UK

${ }^{2}$ Modelling and Economics Unit, National Infections Service, Public Health

England, London, UK

Full list of author information is available at the end of the article
}

(c) The Author(s). 2020 Open Access This article is distributed under the terms of the Creative Commons Attribution 4.0 International License (http://creativecommons.org/licenses/by/4.0/), which permits unrestricted use, distribution, and reproduction in any medium, provided you give appropriate credit to the original author(s) and the source, provide a link to the Creative Commons license, and indicate if changes were made. The Creative Commons Public Domain Dedication waiver (http://creativecommons.org/publicdomain/zero/1.0/) applies to the data made available in this article, unless otherwise stated. 


\section{Background}

For several decades now, it has been known that antibiotic resistance (ABR) among human pathogens is detrimental to health and economic wellbeing [1-3]. International recognition of its threat to modern medicine and society has increased in recent years [4-7]. Several national and international working groups have proposed actions to mitigate its further development, with recommendations including novel funding structures for new antibiotic research and development, development and use of technologies like diagnostics and vaccines that may reduce the need for antibiotics, education to enhance antibiotic stewardship as well as better infection control practices such as ensuring universal access to sanitation, hygiene and safe water [4-7].

Many of the societal conditions that have increased the threat of ABR, such as a lack of investment in antibiotic development and antibiotic overuse, stem from market failure, i.e. the private interests of individuals conflicting with the public interests of society. When used appropriately to treat bacterial infections, antibiotics generate private (individual) benefits by expediting infection clearance and recovery from associated illness, whilst also generating public benefits by reducing the spread of infection across the rest of the population (positive externalities). However, these public benefits are usually outweighed by the costs that fall on others who do not use them (negative externalities) - their use can select for bacteria with more resistance, hence eroding the effectiveness of future antibiotic use. In other words, using antibiotics consumes the global stock of antibiotic effectiveness, making antibiotics less beneficial to everyone who uses them. Additionally, antibiotics confer no benefits against viral infections (and indeed bacterial infections that are resistant to that antibiotic). Since there is usually uncertainty about the aetiology and susceptibility of an infection, patients may demand antibiotic prescriptions and their prescribers are often incentivised to respond to this demand whether it be for a bacterial or viral infection.

Because self-interested antibiotic consumers have little motivation to conserve the global stock of antibiotic effectiveness, most of the recommended interventions to combat ABR are unlikely to succeed without government intervention at the national and international levels. Indeed, even when prescribers act as custodians for antibiotic consumption, they are predicted to prescribe antibiotics to patients even when they only have a small chance of benefit [8].

To correct these market failures and align individual and societal interests, governments (and other healthcare funders such as donors and private insurers) may incentivise prudent antibiotic use through taxes, subsidies and regulations, and fund research in antibiotics and other technologies [9]. However, the scale of these interventions needs to be calibrated to the size of the negative externality, such that it reflects the social value of prolonging antibiotic effectiveness. Striking this balance requires an accurate understanding of the economic cost of ABR [10].

Several reviews have examined the cost of ABR. In particular, five reviews covering the periods 1995-2009 [11], 1987-2000 [12], 2000-2012 [13], 2013-2015 [14] and 2000-2016 [15] found 36, 21, 24, 11 and 8 studies, respectively, assessing the cost of $\mathrm{ABR}$ and/or the costeffectiveness of related interventions. The reviews highlighted methodological shortcomings and biases in the literature as well as challenges in extrapolating study findings to a societal scale and to the long term. In particular, the heterogeneity in methods and quantitative results across different studies complicates meaningful comparisons $[11,14,16,17]$; this heterogeneity is present even when restricting comparisons to studies of a particular organism within the hospital setting [18].

Despite these issues in interpreting and quantifying the costs of ABR, none of the reviews provided detailed proposals of how the evidence gaps and study heterogeneities could be addressed in future studies. Indeed, a lack of certainty on the current and potential future economic burden of ABR, especially in low- and middleincome countries, has been recognised to have hindered international action [4].

Several estimates have recently been made of the global ABR burden to present the case for investing in measures to combat $\operatorname{ABR}[7,19,20]$. These global estimates were performed largely independently of the hospital-based literature, relying instead on international surveillance databases that have been noted to suffer from representativeness issues, confounding and biasedness around attributable mortality and ABR prevalence as well as contestable costing assumptions [21]. Furthermore, quantifying the economic burden of $\mathrm{ABR}$ on its own is of little value for decisionmaking unless it can inform estimates of the impact that different interventions can have on this burden.

To overcome these evidence gaps, we present a conceptual framework that can act as a roadmap for future studies to describe how they can reduce bias and be extended in time, perspective, scope and space. We use this framework to develop comprehensive recommendations for the design of future studies that will allow policy decisions based on a clearer and more consistent methodology as well as on more comprehensive evidence. Our framework is supplemented by a rapid methodological review of studies that consolidates articles in previous reviews on ABR costs and the impact of ABR-related interventions.

\section{Methods}

\section{Conceptual framework}

Previous reviews [11-15] have highlighted methodological shortcomings in the ABR cost literature, including 
heterogeneity in methodological choices [11, 14, 15], biases in study design and analysis [11, 14], lack of evidence outside high-income $[12,15]$ and hospital $[12,13]$ settings, and failure to consider the future consequences of ABR [13]. We used these critiques to develop a conceptual framework of how current studies could be strengthened and extended to address these shortcomings. This was supplemented by additional deductive epidemiological and economic reasoning. The deductive reasoning was guided by the literature on causal inference $[14,22-26]$, perspective and scope of economic impact [27], and opportunity costs [28]. We then conducted a rapid methodological review to (1) extract broad features of $A B R$ cost studies relevant to the methods they use, (2) survey the methods used to cost ABR and (3) examine the extent to which these methods addressed methodological shortcomings. A narrative synthesis of these methods and their limitations was developed and then used to further modify our conceptual framework.

\section{Rapid methodological review}

To inform the conceptual framework, we conducted a rapid methodological review of published and grey literature. For published literature, we searched PubMed and Ovid MEDLINE for all studies up to November 4th, 2019 (see Additional file 1 for search terms). For grey literature, the websites for the World Bank (www.worldbank.org), the European Centre for Disease Prevention and Control (www.ecdc.europa.eu), and the Centre for Infectious Disease Research and Policy (www.cidrap.umn.edu) were examined. We also reviewed the reference lists of five related reviews [11-15]. Studies were not screened in duplicate.

We included all English-language articles (including conference abstracts in peer-reviewed journals) that quantified the cost of ABR from any economic perspective, including papers that quantified these costs as part of an economic evaluation of an intervention to reduce ABR. Both primary data and secondary data analyses were included as long as real costs were an outcome. We included studies that calculated the incremental costs of treating patients with resistant infections relative to either treating patients with a susceptible infection or no infection at all.

Exclusion criteria were (1) studies about ABR in Mycobacterium tuberculosis alone (due to the large volume of this literature using techniques relevant to tuberculosis alone) or non-bacterial pathogens only; (2) studies about bacteria in non-human species alone; (3) reviews, commentaries or theoretical papers that did not estimate a cost associated with ABR that is applicable in a realworld setting; (4) studies that calculated the cost of an intervention (e.g. use of an antibiotic) in the presence or absence of ABR rather than the actual cost of ABR; (5) studies that calculated the cost in terms of total antibiotic use and/or prescription expenditure alone rather the cost associated with a resistant infection; and (6) studies that were not accessible to the authors.

Articles that discussed approaches to quantify costs but did not present numerical results were also examined to inform the wider discussion.

The data extracted from each study is shown in Additional file 2. Descriptive summary statistics were calculated on publication date, country, healthcare setting, economic perspective, bacterial species and study design. Full text papers were read for details on study design and recommendations. A reporting checklist of the review methodology is shown in Additional file 3.

\section{Results of rapid methodological review Descriptive results}

We found 6347 articles from combining the database search and references from previous reviews. Of these, 110 articles were included following abstract and fulltext review (Fig. 1; details in Additional file 2), including 43 articles that had not been included in any previous review.

The articles were published during 1998-2019, with half $(55 / 110)$ being published since 2011. Most (91/110) presented results for high-income countries only, with almost half (48/110) from the United States. Only 12 were from low- and middle-income countries (Brazil, China, Columbia, Ethiopia, India, Senegal, Thailand and Turkey), while 7 included multi-country results. Most (95/110) were set in hospitals (8 in intensive care units), with the remainder being from community care (either acute or long-term) or mixed settings. Most (97/110) used a healthcare provider or payer perspective, with the remainder using either a societal perspective $(8 / 110)$ or multiple perspectives (5/110). The most common (87/ 110) method for costing was using pairwise matching or regression on a patient cohort, while the remaining studies used a cohort exclusively of patients with resistant infections (1/110), ecological analysis or meta-regression of multiple studies (4/110), or mathematical modelling $(18 / 110)$ to estimate costs.

Around half (52/110) examined Gram-positive bacteria alone, with Staphylococcus aureus, Enterococci and Streptococcus pneumoniae being the most common. Fewer (29/ 110) examined Gram-negative bacteria alone, with Enterobacteriaceae, Pseudomonas aeruginosa and Acinetobacter baumannii being the most common. The remainder looked at mixed groups of patients with both Gram-positive and Gram-negative bacteria.

\section{Hospital-based studies}

Similar to previous reviews $[12-15,22]$, we found that most studies focused solely on treatment costs incurred by hospital patients with antibiotic-resistant infections, using one of two designs: 
2,620 Citations in Ovid MEDLINE to $17 \mathrm{Dec} 17$ 1,839 Citations in PubMed to $17 \mathrm{Dec} 17$

1,023 Citations in Ovid MEDLINE 18 Dec 17 - 4 Nov 19

839 Citations in PubMed 18 Dec 17 - 4 Nov 19 Total 6,321 Citations
88 Articles identified from references in five reviews: Cohen et al. (2010), Wilton et al. (2002), Smith and Coast

(2012), Naylor et al. (2018), and Founou, Founou, and Essack (2017)

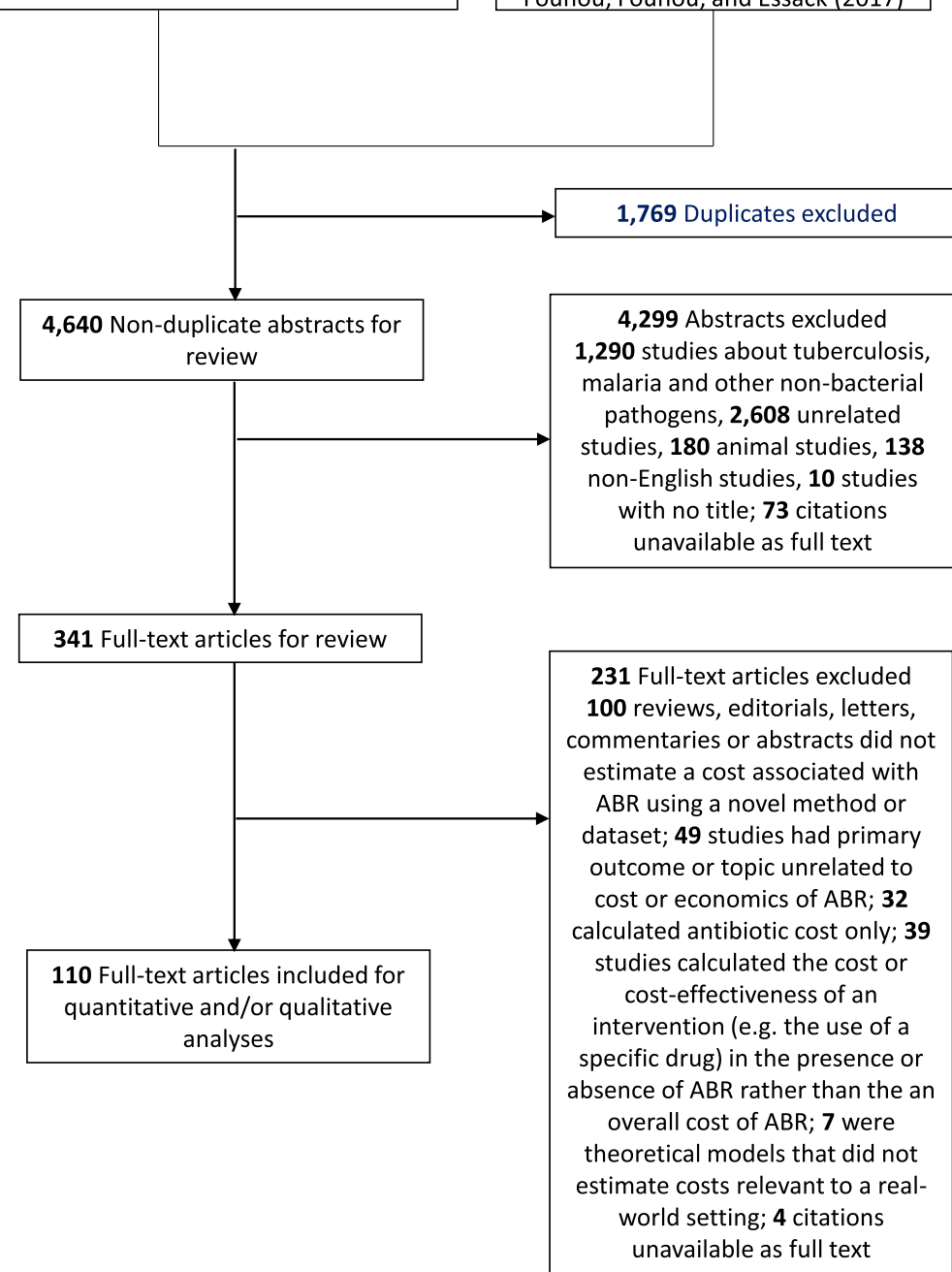

Fig. 1 PRISMA flow diagram showing the review process

- A matched cohort design, where patients with antibiotic-resistant and antibiotic-susceptible infections (or no infection at all) are matched and their cost outcomes compared. Matching is based on patient characteristics and differs widely across studies; some have matched only on patient age and gender, while others have used diagnostic codes, severity-of-illness scores or length of stay from admission to infection onset. However, such studies rarely explore whether the matching characteristics are good indicators of the risk of acquiring an antibiotic-resistant infection [22].

- Regression on a patient cohort to link the presence of an antibiotic-resistant infection with cost-related explanatory variables. In both cases, the outcome variable is treatment costs (calculated using hospital charges and/or standard reimbursement tariffs) or an intermediate outcome such as length of stay, which is then used to calculate costs. The latter approach may underestimate costs by ignoring other cost elements that may be greater for antibioticresistant infections such as testing and prescription costs, management of complications, and isolation ward and intensive care stays [18].

Many studies suffer from methodological shortcomings that may either underestimate or overestimate of the actual cost of ABR, as has been pointed out previously [14, 17, 23]. These shortcomings include (1) unmeasured baseline confounding (not adjusting for differences in the characteristics 
of patients with antibiotic-resistant, antibiotic-susceptible or no infection that affect their clinical outcomes or treatment costs), (2) time-dependent confounding (patients with antibiotic-resistant, antibiotic-susceptible or no infections have different changes to their characteristics such as health between the time of admission and acquiring an infection) [24, 25], (3) time-dependent bias (patients with longer stays being more likely to acquire antibiotic-resistant infections) [25], and (4) model misspecification (use of inappropriate models to relate variables to outcomes, such as the use of Cox regression models even though the proportional hazards assumption is rarely valid for cost outcomes) [26].

The literature in this area has shown methodological improvements over time, with greater use of techniques that can correct for time-dependent biases, such as survival models incorporating infection as a time-dependent predictor and multi-state models [29]. However, few studies adjust for potential time-varying confounding when focusing on hospital-acquired cases, using g-methods such as marginal structural models with inverse probability weighting [25] or nested g-formulae [24]. In contrast to standard regression methods and multistate models, gmethods can provide unbiased estimates of an exposure if there is time-varying confounding that is also affected by the exposure, provided that confounding is accurately measured.

The use of regression and propensity score matching rather than paired cohorts has also increased, which should reduce residual confounding since paired cohorts can only control for a limited selection of variables. Instrumental variable approaches may offer a more powerful approach to correct for observable and unobservable confounders [22]. However, none of the reviewed studies used suitable instruments. It may be possible to use rapid policy shifts, such as changes to hospital cleaning regimens, as instruments, but these shifts would need to be sufficiently large and may be confounded by other time trends.

\section{Conceptual framework}

A major limitation of hospital-based studies is that, on their own, they are insufficient to fully capture ABR economic burden on a national or global level or to assess the impact of interventions against the development of ABR. The conceptual framework proposed describes how they can be extended in time, perspective, scope and space (Fig. 2).

\section{Extension in time: from the present to the long term}

Based on present trends, the prevalence of ABR, and especially multi-drug resistance, is expected to rise [30-32]. However, most estimates of current ABR economic burden do not project estimates into the future, and hence fail to adequately capture the value of interventions that may avert catastrophic future scenarios.
A few studies have taken scenario-based approaches by (1) assuming that future ABR prevalence and/or disease prevalence will increase by arbitrary amounts simply to explore what the consequences of such scenarios would be [7, 19, 20], (2) assuming that all currently susceptible bacterial strains will acquire $A B R$ in the future [33], or (3) linearly projecting past data on disease incidence and ABR prevalence [31, 32].

Even the most extreme scenarios may not represent the worst case, because these projections do not account for new resistances that bacteria may acquire, including resistance to current last-resort antibiotics. If this happens, then the cost of developing new antibiotics or antibiotic classes needs to be incorporated. Otherwise, some analysts have speculated that hospital procedures, such as organ transplantation and cancer chemotherapy, will become risky to perform because of untreatable infections. Approaches to costing such scenarios have been discussed $[16,19,34]$, but no study has presented quantitative results of such calculations.

\section{Extension in perspective: from the healthcare payer to society} Most hospital-based studies only consider ABR costs from the perspective of the healthcare provider (e.g. the hospital providing treatment). Other perspectives are arguably relevant to decision-makers considering whether to fund investments with national and global implications such as developing a new antibiotic.

One such perspective is that of the patient's household. If $A B R$ results in longer hospital stays and more complex procedures, then this may increase household out-of-pocket costs such as co-payments for treatment, transport costs, caregiver accommodation costs and childcare costs. Patients and caregivers may miss work and lose income. These costs may be especially large (in comparison to existing income or wealth) for poorer patients, especially those in countries without universal health coverage [35]; none of the reviewed papers considered these distributional perspectives. Such distributional concerns should also be considered in the use of interventions to correct for market failures in antibiotic use. For instance, taxing antibiotics may particularly burden the poor since the demand for antibiotics is relatively income inelastic [36]; therefore, compensatory measures may be appropriate such as funding healthcare services and improvements in infection prevention strategies that will reduce the overall need for antibiotics [10].

A further dimension of household economic burden is the value of avoiding pain, suffering and worry to patients and caregivers, including the value of avoiding premature mortality. In economic evaluations, this is usually done by either (1) monetising this value by eliciting people's willingness to pay to avoid morbidity and mortality or (2) valuing it using a separate metric such 

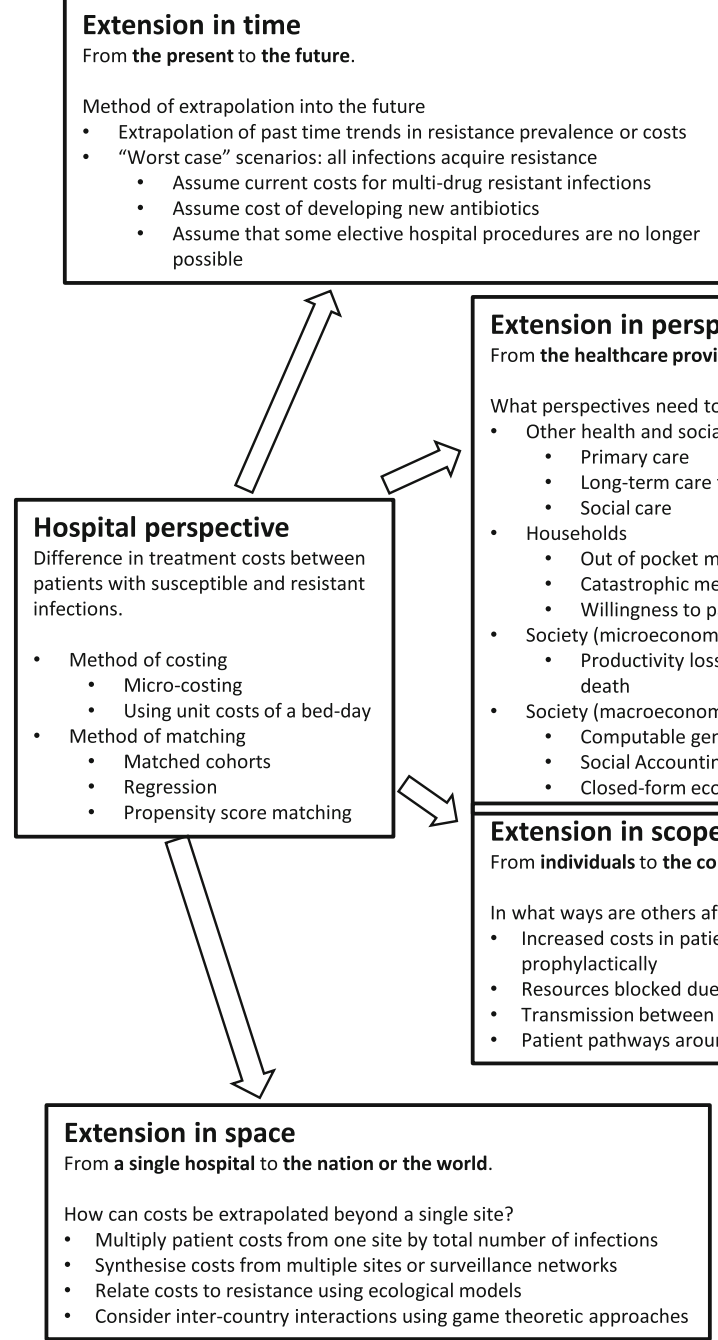

Fig. 2 Conceptual framework outlining options discussed in the text to extend the scope of studies estimating the costs of antibiotic resistance (see text for references)

as quality- or disability-adjusted life years. As an example, Phelps [37] costed each avoided death as having a value of US\$1 m (2 m in $2017 \mathrm{I} \$$ ). Capturing household and psychosocial aspects of ABR burden is especially important in low- and middle-income settings where treatment costs and hospitalisation rates may be lower (due to low labour costs and poor healthcare access, respectively), but the human cost of ABR remains high.

The societal perspective is the broadest and includes the effect that morbidity and mortality have on economic production. Only 8/110 of the reviewed studies included explicitly mentioned incorporating productivity costs; those that did, concluded that productivity costs were greater than direct medical costs. Most (6/110) used the human capital method, whereby any time lost from work as a result of death, sickness or caregiving is converted into production costs by multiplying either by the average wage or by the national GDP per capita; none subtracted future medical or non-medical consumption as recommended by some economists [38]. Two studies argue that the human capital method underestimates the impact of $\mathrm{ABR}$ to society because it ignores the broader macroeconomic impact of reduced labour supply, increased healthcare demand and reduced consumption due to sickness, disability, premature mortality and fear of infection. Increased rates of $\mathrm{ABR}$ are likely to have a detrimental effect on unemployment, inflation, total factor productivity and, ultimately, national income [9]. There are a number of ways through which studies have tried to incorporate these macroeconomic effects - capturing labour and capital stocks with the Cobb-Douglas function [19], modelling intersectoral flows with Social Accounting Matrix methods $[19,20]$ and dynamically capturing economic shocks with Computable General Equilibrium methods [9, 39]. 
Additionally, when taking the societal perspective, disease not resulting in hospitalisation (i.e. treated in the community, in primary care or in outpatient clinics) becomes important because this may still result in productivity losses even if direct healthcare costs are low.

\section{Extension in scope: from the individual patient to the community}

Most studies have considered only the difference in costs of treating patients with antibiotic-susceptible and antibioticresistant infections; however, ABR can also increase costs for patients without antibiotic-resistant infections. For instance, patients with infections for which ABR is widespread are routinely given costly ABR tests and/or empirically prescribed antibiotics that are costlier and have worse side effects than first-line antibiotics. One study found that ABR contributed to a $22 \%$ increase in per prescription antibiotic spending on otitis media [40].

Some antibiotics are given prophylactically to patients particularly susceptible to infections such as pregnant women [41] and cancer or surgical patients [34, 42]; loss of antibiotic effectiveness will decrease prophylaxis effectiveness and worsen patient outcomes [34]. These effects can be translated into costs [16], although no paper we reviewed has done this explicitly.

By considering only the incremental cost of treating antibiotic-resistant infections compared to antibioticsusceptible infections, most studies imply that, even if ABR was eliminated, patients would still be infected by a susceptible infection. However, bacterial transmission is often driven by the ineffectiveness or slow effectiveness of antibiotic treatment, causing antibiotic-susceptible strains to spread more slowly; thus, reducing ABR may also reduce overall infection incidence.

Further spill-overs occur from the opportunity costs associated with antibiotic resistance to others in the community who may be unable to access timely healthcare when resources, such as hospital beds, are blocked by patients with longer stays due to resistant infections. These opportunity costs can be expressed in terms of monetary time costs or in terms of impact on hospital revenues [43] or the health of other patients [28].

Finally, resistant infections arise and are transmitted within and between humans, non-human animals and the environment. Patients with resistant infections can move between different healthcare sectors such as hospitals, intermediate/long-term care and the community. These effects can influence the impact of interventions; the methods to capture them are described in more detail in the section on "The impact of interventions" below.

\section{Extension in space: from one hospital to national/global estimates}

Antibiotic-resistant organisms cross boundaries between host species (humans and other animals), hospitals and countries. Single hospital studies may be useful to estimate the cost of a localised outbreak, but the impact of policy instruments usually needs to be considered at the national or even global level. Game-theoretic analyses suggest that optimal antibiotic allocation requires cooperation between countries rather than allowing individual patients or even countries to act in their own self-interest [44].

Only 18/110 of the reviewed studies (of which only 7 were published before 2018) and a further 4 studies found in the grey literature extrapolated findings from study sites to countries or multi-country groupings (Table 1). The most common approach is to multiply incremental costs in study sites by the total number of antibiotic-resistant cases across the entire geography. The shortcoming of this approach is that data from a single hospital or even several hospitals often lack external validity [32]. Quantitative comparisons of the literature have found substantial differences in costs between studies [11, 17, 22]. Another approach is to synthesise information from multiple studies as was done in crossEuropean analyses [6]. Since studies are heterogeneous, in the long term, multi-centre studies with a common methodology may improve both statistical power and validity beyond study settings [22].

A separate approach has been to rely on national [48, $52,53,55]$ or global $[19,20]$ surveillance databases rather than individual sites. This offers greater external validity but may only be accurate in countries with representative patient data on healthcare utilisation, prescribing and antibiotic susceptibility, ideally linked to account for dependencies in these variables. The validity of global antibiotic use databases has been questioned, particularly in resource-poor settings, given the difficulty of capturing antibiotic supply from informal providers [58, 59]. Furthermore, cultures are less frequently taken in resourcepoor settings and often only when patients do not seem to respond to empirical antibiotic therapy, leading to inflated estimates of ABR prevalence [59]. A better approach may be to estimate $A B R$ costs using large prospective population-based or multi-centre studies where antibiotic susceptibility is tested in all patients seeking healthcare for acute infections.

When patient-level data are not available, studies have related ABR with costs on an ecological level (by subnational region $[60,61]$ or country [35]). The usual approach is to linearly regress the proportion of isolates that are resistant with healthcare expenditure (alongside other explanatory variables) $[35,60]$. In some cases, an intermediate outcome, such as overall pathogen prevalence [61], is the primary outcome variable, which is then converted into costs. 
Table 1 Estimates of national, multinational and global costs of antibiotic resistance. Costs were inflated using local GDP deflators and converted to 2018 international dollars (I\$) using purchasing power parities, both from data published by the World Bank and $\mathrm{OECD}$

\begin{tabular}{|c|c|c|c|c|c|}
\hline Study & Geography & Pathogens & Costs in original currency & Costs in $2018 \mathrm{I \$}$ & Costs considered \\
\hline \multicolumn{6}{|c|}{ Studies in the grey literature } \\
\hline ECDC and EMEA [6] & $\begin{array}{l}\text { EU, } \\
\text { Iceland, } \\
\text { Norway }\end{array}$ & $\begin{array}{l}\text { S. aureus, Enterococcus } \\
\text { spp., S. pneumoniae, E. } \\
\text { coli, Klebsiella spp., P. } \\
\text { aeruginosa }\end{array}$ & 1.5 bn/year EUR (2007) & $2.1 \mathrm{bn} /$ year & $\begin{array}{l}\text { Increased treatment costs, reduced } \\
\text { productivity and labour supply due } \\
\text { to morbidity and premature } \\
\text { mortality }\end{array}$ \\
\hline KPMG [19] & $\begin{array}{l}\text { EU, } \\
\text { Iceland, } \\
\text { Norway } \\
\text { Global }\end{array}$ & $\begin{array}{l}\text { E. coli, K. pneumoniae, } \\
\text { S. aureus, HIV, TB, malaria }\end{array}$ & $\begin{array}{l}1.6 \text { bn/year EUR (2012) } \\
1.66-6.08 \% \text { of global } \\
\text { GDP in } 2050\end{array}$ & 2.3 bn/year & $\begin{array}{l}\text { Increased treatment costs, reduced } \\
\text { productivity and labour supply due } \\
\text { to morbidity and premature } \\
\text { mortality }\end{array}$ \\
\hline RAND Europe [20] & Global & $\begin{array}{l}\text { E. coli, K. pneumoniae, } \\
\text { S. aureus, HIV, TB, malaria }\end{array}$ & $\begin{array}{l}0.5-6.0 \text { tn USD ( } 2011) \\
\text { per year in } 40 \text { years } \\
(0.14-1.9 \% \text { of global } \\
\text { GDP) }\end{array}$ & $\begin{array}{l}0.6-6.8 \mathrm{tn} \text { per year } \\
\text { in } 40 \text { years }\end{array}$ & $\begin{array}{l}\text { Reduced labour supply and } \\
\text { productivity due to increased } \\
\text { morbidity, mortality and caregiving } \\
\text { Reduced inter-sectoral transactions } \\
\text { and trade }\end{array}$ \\
\hline World Bank [7] & Global & Any & $\begin{array}{l}1.0-3.4 \text { tn USD (2017) } \\
\text { per year in } 2030 \\
(1.1-3.8 \% \text { of global } \\
\text { GDP) }\end{array}$ & $\begin{array}{l}1.0-3.5 \mathrm{tn} 1 \$ \text { per } \\
\text { year in } 2030\end{array}$ & $\begin{array}{l}\text { Reduced labour supply due to } \\
\text { premature mortality }\end{array}$ \\
\hline \multicolumn{6}{|c|}{$\begin{array}{l}\text { Studies in the rapid review } \\
\text { of published literature }\end{array}$} \\
\hline Chen et al. [45] & Ethiopia & S. pneumoniae & 15.8 m/year USD (2017) & $16.2 \mathrm{~m} /$ year & $\begin{array}{l}\text { Increased treatment costs and } \\
\text { productivity losses due to morbidity } \\
\text { and premature mortality }\end{array}$ \\
\hline Chesson et al. [46] & USA & N. gonorrhoeae & 378 m/year USD (2016) & 395 m/year & Increased treatment costs \\
\hline de Kraker et al. [32] & $\begin{array}{l}31 \\
\text { European } \\
\text { countries }\end{array}$ & $\begin{array}{l}\text { Bloodstream infections } \\
\text { caused by MRSA } \\
\text { and G3CREC }\end{array}$ & 62 m/year EUR (2007) & $87 \mathrm{~m} /$ year & Increased length of hospital stay \\
\hline Elbasha [47] & USA & Any & $\begin{array}{l}0.4-19 \text { bn/year USD } \\
\text { (1996) }\end{array}$ & 0.6-29 bn/year & $\begin{array}{l}\text { "Deadweight loss": reduced } \\
\text { antibiotic effectiveness leading to } \\
\text { poorer treatment outcomes due to } \\
\text { overprescribing antibiotics }\end{array}$ \\
\hline Johnston et al. [48] & $\begin{array}{l}\text { United } \\
\text { States }\end{array}$ & $\begin{array}{l}\text { Multi-drug resistant } \\
\text { organism }\end{array}$ & $\begin{array}{l}\text { 2.39-3.38 bn/year USD } \\
(2017)\end{array}$ & 2.45-3.46 bn/year & Increased treatment costs \\
\hline Lee et al. [49] & USA & $\begin{array}{l}\text { Community-associated } \\
\text { MRSA }\end{array}$ & $\begin{array}{l}\text { Healthcare: } 478 \text { m/year } \\
\text { USD (2011) } \\
\text { Society: } 2.2 \text { bn/year } \\
\text { USD (2011) }\end{array}$ & $\begin{array}{l}\text { Healthcare: } 539 \mathrm{~m} / \\
\text { year } \\
\text { Society: } 2.5 \text { bn/year }\end{array}$ & $\begin{array}{l}\text { Increased treatment costs and } \\
\text { productivity loss due to morbidity } \\
\text { and premature mortality }\end{array}$ \\
\hline Michaelidis et al. [50] & USA & Any & 4.4 bn/year USD (2013) & $4.8 \mathrm{bn} /$ year & $\begin{array}{l}\text { Cost of antibiotic use and } \\
\text { stewardship }\end{array}$ \\
\hline Naylor et al. [29] & England & E. coli & $\begin{array}{l}\text { Third-generation } \\
\text { cephalosporin: } \\
\text { 366,600/year GBP } \\
\text { (2012) Piperacillin/ } \\
\text { tazobactam: 275,4000/ } \\
\text { year GBP (2012) }\end{array}$ & $\begin{array}{l}\text { Third-generation } \\
\text { cephalosporin: } 578, \\
\text { 000/year } \\
\text { Piperacillin/ } \\
\text { tazobactam: } 434,000\end{array}$ & Increased treatment costs \\
\hline Phelps [37] & USA & Any & $\begin{array}{l}0.15-3 \mathrm{bn} / \text { year } \\
\text { USD (1984) }\end{array}$ & $0.3-6.3 \mathrm{bn} /$ year & Treatment costs, mortality \\
\hline Phodha et al. [51] & Thailand & $\begin{array}{l}\text { Nosocomial infections } \\
\text { due to five bacterial } \\
\text { species }\end{array}$ & $\begin{array}{l}\text { Healthcare: } 2.3 \text { bn/year } \\
\text { USD (2012) } \\
\text { Society: } 4.2 \text { bn/year } \\
\text { USD (2012) }\end{array}$ & $\begin{array}{l}\text { Healthcare: } 2.5 \mathrm{bn} / \\
\text { year } \\
\text { Society: } 4.6 \text { bn/year }\end{array}$ & $\begin{array}{l}\text { Increased treatment costs } \\
\text { Increased societal costs } \\
\text { (components not } \\
\text { reported) }\end{array}$ \\
\hline Shrestha et al. [52] & $\begin{array}{l}\text { USA and } \\
\text { Thailand }\end{array}$ & Any & $\begin{array}{l}\text { USA: } 2.9 \text { bn/year } \\
\text { USD (2016) } \\
\text { Thailand: } 0.5 \text { bn/year }\end{array}$ & $\begin{array}{l}\text { USA: } 3.0 \text { bn/year } \\
\text { Thailand:0.5 bn/year }\end{array}$ & $\begin{array}{l}\text { Increased treatment costs and } \\
\text { productivity loss due to } \\
\text { morbidity and premature mortality }\end{array}$ \\
\hline
\end{tabular}


Table 1 Estimates of national, multinational and global costs of antibiotic resistance. Costs were inflated using local GDP deflators and converted to 2018 international dollars (\$\$) using purchasing power parities, both from data published by the World Bank and OECD (Continued)

\begin{tabular}{|c|c|c|c|c|c|}
\hline Study & Geography & Pathogens & Costs in original currency & Costs in $20181 \$$ & Costs considered \\
\hline Smith et al. [39] & UK & MRSA & $\begin{array}{l}0.4-1.6 \% \text { of national } \\
\text { GDP, equivalent to } \\
3-11 \text { bn GBP (1995) }\end{array}$ & $6.5-24.0 \mathrm{bn}$ & $\begin{array}{l}\text { Reduced labour supply and } \\
\text { productivity, } \\
\text { leading to less capital investment } \\
\text { and } \\
\text { lowered productivity }\end{array}$ \\
\hline Thorpe et al. [53] & USA & Any & 2.2 bn/year USD (2016) & $2.3 \mathrm{bn} /$ year $1 \$$ & $\begin{array}{l}\text { Increased treatment costs due to } \\
\text { morbidity }\end{array}$ \\
\hline Tillekeratne et al. [54] & Sri Lanka & Any & 229 m/year USD (2017) & $235 \mathrm{~m} /$ year & $\begin{array}{l}\text { Not specified - costs extrapolated } \\
\text { from US } \\
\text { and Thai studies }\end{array}$ \\
\hline Touat et al. [55] & France & Gram-negative bacteria & 287 m/year EUR (2015) & 397 m/year & Increased treatment costs \\
\hline $\begin{array}{l}\text { US Congress, Office } \\
\text { of Technology } \\
\text { Assessment [56] }\end{array}$ & USA & $\begin{array}{l}\text { Nosocomial infections } \\
\text { due to six bacterial } \\
\text { species }\end{array}$ & 1.3 bn/year USD (1992) & $2.1 \mathrm{bn} /$ year & Hospital treatment costs \\
\hline Zhen et al. [57] & China & $\begin{array}{l}\text { Intra-abdominal bacterial } \\
\text { infections }\end{array}$ & $\begin{array}{l}\text { Healthcare: } 37 \text { bn/year } \\
\text { CNY (2015) } \\
\text { Society: } 111 \text { bn/year } \\
\text { CNY (2015) }\end{array}$ & $\begin{array}{l}\text { Healthcare: } 12 \mathrm{bn} / \\
\text { year } \\
\text { Society: } 35 \text { bn/year }\end{array}$ & $\begin{array}{l}\text { Increased treatment costs, } \\
3 x \text { multiplier for } \\
\text { societal costs }\end{array}$ \\
\hline
\end{tabular}

bn billion, CNY Chinese Yen, ECDC European Centre for Disease Prevention and Control, EMEA European Medicines Agency, G3CREC third-generation cephalosporin-resistant E. coli, MRSA methicillin-resistant Staphylococcus aureus, TB tuberculosis, tn trillion, USD US Dollar

\section{The impact of interventions}

While most studies have focused on the overall ABR economic burden, some have examined the impact and cost-effectiveness of interventions that could potentially affect ABR. Most of these consider ABR alone as an exogeneous factor affecting the cost-effectiveness of an intervention but not itself influenced by the intervention. For instance, many cost-effectiveness evaluations of antibiotics have incorporated the effect of ABR on the effectiveness of antibiotic treatment [62] or the types of antibiotics that can be used [63]. Similarly, cost-effectiveness studies of interventions to reduce antibiotic consumption (such as stewardship programmes and rapid diagnostic tests) have typically considered intervention impact on antibiotic volume and costs. However, few studies have considered the potential impact of antibiotic consumption on (1) reducing $A B R$ by preventing onward transmission of a bacteria susceptible to the antibiotic (positive externality) and/or (2) inducing ABR by increasing selective pressure (negative externality).

Some studies have captured these externalities using descriptive statistical approaches such as (1) using empirical data to evaluate the impact of a discrete intervention affecting antibiotic consumption (such as introduction of a stewardship programme) on ABR prevalence or treatment cost [64]; (2) estimating a fixed ratio between antibiotic consumption and ABR costs (or an intermediate proxy such as ABR prevalence or hospital bed-days used to treat infection with a particular pathogen) [54]; or (3) fitting a statistical model, such as linear correlation between antibiotic consumption and $\mathrm{ABR}$ costs (or an intermediate proxy), using data sampled over several countries and/or years [52].

These methods require an estimate of ABR costs. In hospital studies, this can be estimated as the cost of treating resistant infections in the hospital [64]. In ecological studies, ABR costs are often regarded as the cost of all antibiotics consumed in a single country and year $[50,65]$. The most sophisticated methods derive from work by Phelps [37], who explicitly modelled market dynamics between antibiotic producers and consumers as well as the relationship between antibiotic consumption and the emergence of ABR. This was then used to estimate the total negative externality of annual antibiotic use in the USA, defined as the welfare loss due to ABR minus the welfare benefits that come from using antibiotics. This model was independently extended by Elbasha [47] and Kaier [66-68].

All the above methods make major simplifying assumptions, as described below:

- Some models assume that resistance against a particular antibiotic is only affected by the use of antibiotics of the same class. In practice, antibiotic use can affect $A B R$ against an antibiotic of a different class. For instance, amoxicillin, which is typically prescribed for respiratory tract infections, is associated with increased trimethoprim and ciprofloxacin resistance in Escherichia coli causing urinary tract infections $[69,70]$. Conversely, higher nitrofurantoin use was found to be associated with lower levels of trimethoprim and amoxicillin 
resistance, potentially due to collateral sensitivity or a negative correlation between resistance genes [69].

- Models relating (human) antibiotic consumption to ABR assume that the relationship is not confounded by between-country differences such as in infection prevention and control measures and agricultural antibiotics use. Reverse causality could play a role in cross-sectional data since physicians may avoid a particular antibiotic if ABR to that antibiotic is known to be high in that population [71]. In some cases, the potential role of reverse causality could be assessed using structural equation models or instrumental variables.

- Some models assume that the relationship is instantaneous, i.e. that a given level of antibiotic use will immediately result in some level of ABR. In practice, bacteria take time to acquire resistant genes and reach a new equilibrium prevalence in a population. Indeed, high levels of ABR may be the cumulative effect of years of antibiotic use, i.e. present antibiotic use may be depleting the health and wellbeing of future generations [72]. Furthermore, future changes in ABR can be unpredictable. While the emergence of mutations conferring ABR to certain antibiotics is predictable to some extent, the timing and impact of the introduction of new ABR genes into mobile genetic elements or widespread bacterial strains is not [10, 73].

- Models often assume that the relationship between antibiotic use and ABR is linear (or can be described with a simple function); this has some basis in ecological observations at the national level [74]. However, investigators using non-linear models suggest that the relationship is more complex and dynamic $[3,75,76]$.

Advanced modelling approaches may circumvent some but not all of these limitations. Time-series approaches to modelling the relationship between population antibiotic use and $A B R$ in hospitals suggest that this relationship is indeed non-linear [77]. Furthermore, machine learning approaches, such as boosted regression trees, can also be used, allowing flexibility in the functional relationship [70].

Dynamic effects, such as time delays and feedback loops, can be captured with transmission dynamic models [45, 78], dynamic Bayesian Markov models [79] or by including lagged covariates into regression analysis. Transmission dynamic models capture the effect of interventions on onward transmission and competition between susceptible and resistant bacterial strains, and can be used to track changes in ABR prevalence over time. Transmission dynamic models with strain competition that incorporate economic outcomes are rare $[45,78$, 80]; one reason is that such models require data on antibiotic use in different settings, acquisition and carriage (duration) of antibiotic resistant bacteria, environmental swabs, movement of patients and contact patterns, rates of infection, and the associated current and future impact on patient outcomes and costs in order to predict the impact of interventions on ABR and the associated costs. However, some of them note that predictions about optimal policy may differ when economic considerations are incorporated into purely epidemiological/ecological models [3].

A key issue around all models is the reversibility of $A B R$, i.e. whether susceptible strains will eventually outcompete resistant strains when reducing selective pressure from antibiotic use. Most ABR mechanisms come with fitness costs that reduce the competitiveness of resistant strains compared to susceptible strains in the absence of antibiotic exposure [68]. However, reductions in antibiotic prescribing have not always led to reductions in ABR prevalence, potentially due to a lack of fitness costs, compensatory mutations that reduce fitness costs, and coselection of ABR genes by other antibiotics. The reversibility of ABR likely depends on the setting, the bacterial species and on whether overall antibiotic use is reduced or one antibiotic is simply replaced by another [81]. Models that assume that ABR is not reversible effectively model antibiotic effectiveness as a non-renewable resource [3, 78]; these models aim to find strategies that obtain the greatest value from antibiotics before their effectiveness in exhausted.

\section{Discussion}

\section{Current evidence base}

While the number of studies that estimate the cost of $\mathrm{ABR}$ is rapidly accumulating, the majority of published studies still ignore several biases and have too narrow a focus to estimate the true cost of ABR. For example, we found no studies that adjusted for time-dependent confounding using an appropriate methodology when estimating the costs attributable to hospital-onset resistant infections nor any studies that examined the impact that future levels of ABR may have on clinical pathways. Completely ignoring time-dependent confounding likely leads to overestimation of the impact of $A B R$ in the hospital setting given that patients that develop an ABR infection have likely deteriorated further between admission and acquisition than patients who remain infection free [23]. Attempting to correct for time-varying confounding using inappropriate methodology, such as standard regression techniques or multi-state models, may only partly remove the indirect effects of early infection that are mediated through the considered confounders, and may also introduce collider-stratification bias, which can lead to either an over- or underestimation of the true effect $[14,23,26]$. 
We also found few studies capturing wider costs beyond hospital treatment costs (such as productivity costs, outof-pocket expenses, opportunity costs of lost bed days and inability to use antibiotics, and costs associated with the value of avoiding suffering), and few studies in low- and middle-income settings. Consequently, it is likely that most studies have overestimated current ABR costs in the hospital setting (because of incomplete control for biases and confounding) but underestimated total ABR costs (because of failure to account for wider societal costs and future consequences of $\mathrm{ABR}$ ).

Lastly, we found a variety of approaches to costing, in line with previous reviews that concluded that heterogeneities in the quality of applied methods in ABR cost studies prevented meaningful comparisons [11, 14, 16-18].

\section{Conceptual framework}

To address the limitations of existing studies, we have developed a conceptual framework to highlight the ideal scope and approaches for ABR cost estimations (Fig. 2). We recognise that an analysis that is robust and comprehensive according to this framework likely cannot be conducted at this time due to limitations in both data and analytical methods. Hence, our framework points to the need for better primary studies and surveillance to inform the development of more methodologically robust models of ABR costs. In Table 2, we outline some recommendations for the field.

\section{Limitations}

The framework was informed by a narrative review of approaches and limitations that studies have taken to costing ABR. A narrative review aims to interpret and critique a large body of literature on a broad question, rather than summarise or synthesise literature on a narrowly focused topic [82]. In this case, it was appropriate because the question we are addressing is wide ranging, approaches to it are still being developed and the literature we reviewed is varied, including commentaries, primary data collection studies, economic evaluations and conceptual models. The narrative review was informed by a rapid literature search to obtain a broad overview of the methods used by relevant papers, combined with a review of references from previous reviews. The rapid methodological review found 110 relevant studies, far more than any other review of the topic in the literature. Nevertheless, the review methodology we used was not as exhaustive or unbiased as a full systematic review. In particular, the search terms and range of databases we searched were relatively limited because of the large number of relevant articles.

Our conceptual framework builds on gaps identified in current ABR estimates as well as on issues that have been previously discussed or that were considered
Table $\mathbf{2}$ List of recommendations for future studies estimating the cost of antibiotic resistance (ABR) and related interventions

\section{Recommendations for primary data collection}

- Capture all economic costs related to ABR in hospital patients, not just the directly observed outcomes such as increased length of stay

- Explore use of g-methods to correct for both time-dependent biases and time-dependent confounders in studies evaluating time-varying exposures in hospital-based studies

- Exhaustively investigate potential confounders that need to be collected and investigated in ABR cost studies, ideally using formal causal inference methods such as causal diagrams

- Collect data on lost earnings and out-of-pocket expenses of patients and caregivers so that the wider household and societal costs of prolonged hospital stay and premature mortality can be captured; this is especially important in settings with high out-of-pocket medical expenses

- Consider reporting measures of the psychosocial burden of suffering to patients and caregivers associated with illness, either by monetising the value of avoided suffering or by reporting this separately in units such as quality- or disability-adjusted life years

- Consider both quality (internal validity) and broader representativeness (external validity) of data collected before extrapolating from study sites to wider regions such as the national or international level; if possible, data from multiple sites should be synthesised using meta-analysis or meta-regression (including geospatial variables, if appropriate)

- Implications of ABR outside the hospital setting should be considered unless they are known to be negligible

Recommendations for further methodological development

- Investigate how levels of ABR may lead to increased costs for everyone, including patients with susceptible infections, those receiving antibiotics prophylactically and patients who are unable to access hospital beds because they are occupied by patients whose hospital stay has been extended by having a resistant infection

- Explore the use of longitudinal data from prospective cohorts or large linked patient databases to understand the relationships between antibiotic use, ABR and costs of ABR

- Ecological methods, such as regression, may allow extrapolation of site- or region-specific costs to a national or global level, adjusting for levels of ABR as well as other variables; however, further research is needed to investigate the implications of model simplifications, such as assuming linear and static relationships between antibiotic use and $A B R$, and the use of alternative modelling methods

- Insights from transmission dynamic models of bacterial ecology and from economic models of antibiotic market dynamics need to be combined in order to inform optimal policies

- Explore ways that long-term projections and macro-economic modelling can be incorporated into economic evaluations of ABR-related interventions

important based on our own experience. Therefore, it is not an exhaustive list of all issues that could be encountered when estimating the costs of ABR.

\section{Conclusion}

There is a clear need for more accurate estimates of the current and future costs attributable to ABR to inform decision-making around justified levels of investment in interventions that address the challenge of increasing ABR. Substantial improvements in methodological 
rigour and extension in time, perspective, scope and space are needed to capture the true costs of ABR in future studies. Furthermore, because better models cannot overcome data limitations, investment in prospective data collection is needed, including measurement of all relevant potential (time-varying) confounders as well as data on ABR infections and their associated costs and health consequences. This is particularly true in lowincome settings where there is currently a clear lack of reliable data. Such studies need careful a priori consideration of potential confounders and biases. While this will be no easy task, strengthening the robustness of evidence on the true costs of ABR is critical to guide local, national and global efforts to address the issue.

\section{Supplementary information}

Supplementary information accompanies this paper at https://doi.org/10. 1186/s12916-020-1507-2.

Additional file 1. Search terms used in the rapid review.

Additional file 2. Data extracted from studies in the rapid review.

Additional file 3. Reporting items checklist based on Table 7.1 in Trico et al. Rapid Reviews to Strengthen Health Policy and Systems: A Practical Guide. Geneva: World Health Organisation; 2017.

\section{Acknowledgements}

Not applicable.

\section{Authors' contributions}

MJ designed the original idea for the article. DNHL and NL conducted the rapid review with input from $\mathrm{MJ}$. All authors interpreted the results, wrote the manuscript and approved the final version.

\section{Funding}

This work was supported by the Bill and Melinda Gates Foundation (OPP1180644) as well as the National Institute for Health Research Health Protection Research Units (NIHR HPRU) in Immunisation at the London School of Hygiene and Tropical Medicine (HPRU-2012-10096) and in Healthcare Associated Infections and Antimicrobial Resistance at the University of Oxford (HPRU-2012-10041) and Imperial College London (HPRU2012-10047), in partnership with Public Health England. The views expressed are those of the authors and not necessarily those of the National Health Service, National Institute for Health Research, Department of Health, or Public Health England.

\section{Availability of data and materials}

Data extracted from the rapid methodological review are included in this published article and in Additional file 2.

\section{Ethics approval and consent to participate}

Not applicable.

\section{Consent for publication}

Not applicable.

\section{Competing interests}

The authors declare that they have no competing interests.

\section{Author details}

'The National Institute for Health Research (NIHR) Health Protection Research Unit in Immunisation, London School of Hygiene \& Tropical Medicine, Keppel Street, London WC1E 7HT, UK. ${ }^{2}$ Modelling and Economics Unit, National Infections Service, Public Health England, London, UK. ${ }^{3}$ School of Public Health, University of Hong Kong, Hong Kong, SAR, China.
${ }^{4}$ Department of Infectious Diseases, Singapore General Hospital, Singapore, Singapore. ${ }^{5}$ Mahidol-Oxford Tropical Medicine Research Unit, Faculty of Tropical Medicine, Mahidol University, Bangkok, Thailand. ${ }^{6}$ Centre for Global Health Research, The Usher Institute for Population Health Science and Informatics, The University of Edinburgh, Edinburgh, UK. ${ }^{7}$ The National Institute for Health Research (NIHR) Health Protection Research Unit in Healthcare Associated Infections and Antimicrobial Resistance, University of Oxford, Oxford, UK. ${ }^{8}$ The National Institute for Health Research (NIHR) Health Protection Research Unit in Healthcare Associated Infections and Antimicrobial Resistance, Imperial College London, London, UK. ${ }^{9}$ Health Economics Research Centre, Nuffield Department of Population Health, University of Oxford, Oxford, UK.

Received: 4 October 2019 Accepted: 31 January 2020

Published online: 06 March 2020

\section{References}

1. Holmberg SD, Solomon SL, Blake PA. Health and economic impacts of antimicrobial resistance. Rev Infect Dis. 1987;9:1065-78. https://doi.org/10. 1093/clinids/9.6.1065.

2. Coast J, Smith RD, Millar MR. Superbugs: should antimicrobial resistance be included as a cost in economic evaluation? Health Econ. 1996:5:21726. https://doi.org/10.1002/(SICI)1099-1050(199605)5:3<217::AIDHEC200>3.0.CO;2-S.

3. Laxminarayan R, Brown GM. Economics of antibiotic resistance: a theory of optimal use. J Environ Econ Manage. 2001;42:183-206. https://doi.org/10. 1006/JEEM.2000.1156.

4. World Health Organization. Global action plan on antimicrobial resistance. Geneva: World Health Organization; 2015. https://apps.who.int/iris/handle/1 0665/193736.

5. O'Neill J. Antimicrobial resistance: tackling a crisis for the health and wealth of nations. Review on antimicrobial resistance. London: Wellcome Trust; 2014.

6. ECDC/EMEA Joint Working Group. The bacterial challenge: time to react. Stockholm: ECDC/EMEA; 2009.

7. The World Bank. Drug-resistant infections: A threat to our economic future. Washington, DC: World Bank; 2017.

8. Colman AM, Krockow EM, Chattoe-Brown E, Tarrant C. Medical prescribing and antibiotic resistance: a game-theoretic analysis of a potentially catastrophic social dilemma. PLoS One. 2019;14:e0215480. https://doi.org/10. 1371/journal.pone.0215480.

9. Smith RD, Yago M, Millar M, Coast J. A macroeconomic approach to evaluating policies to contain antimicrobial resistance. Appl Health Econ Health Policy. 2006;5:55-65. https://doi.org/10.2165/00148365200605010-00007.

10. Roope LSJ, Smith RD, Pouwels KB, Buchanan J, Abel L, Eibich P, et al. The challenge of antimicrobial resistance: what economics can contribute. Science. 2019;364:eaau4679. https://doi.org/10.1126/science. aau4679.

11. Cohen B, Larson EL, Stone PW, Neidell M, Glied SA. Factors associated with variation in estimates of the cost of resistant infections. Med Care. 2010;48: 767-75. https://doi.org/10.1097/MLR.0b013e3181e358b9.

12. Wilton P, Smith R, Coast J, Millar M. Strategies to contain the emergence of antimicrobial resistance: a systematic review of effectiveness and costeffectiveness. J Health Serv Res Policy. 2002;7:111-7. https://doi.org/10.1258/ 1355819021927764.

13. Smith $\mathrm{RD}$, Coast $\mathrm{J}$. The economic burden of antimicrobial resistance: why it is more serious than current studies suggest. Technical report. London: London School of Hygiene \& Tropical Medicine; 2012. https://doi.org/10 17037/PUBS.00639028.

14. Naylor NR, Atun R, Zhu N, Kulasabanathan K, Silva S, Chatterjee A, et al. Estimating the burden of antimicrobial resistance: a systematic literature review. Antimicrob Resist Infect Control. 2018;7:58. https://doi.org/10.1186/ s13756-018-0336-y.

15. Founou RC, Founou LL, Essack SY. Clinical and economic impact of antibiotic resistance in developing countries: a systematic review and metaanalysis. PLoS One. 2017;12:e0189621. https://doi.org/10.1371/journal.pone. 0189621.

16. Smith $\mathrm{R}$, Coast J. The true cost of antimicrobial resistance. BMJ Br Med J. 2013;346:1-5. https://doi.org/10.1136/bmj.f1493. 
17. Gandra S, Barter DM, Laxminarayan R. Economic burden of antibiotic resistance: how much do we really know? Clin Microbiol Infect. 2014;20: 973-80. https://doi.org/10.1111/1469-0691.12798.

18. Antonanzas F, Lozano C, Torres C. Economic features of antibiotic resistance: the case of methicillin-resistant Staphylococcus aureus. Pharmacoeconomics. 2015;33:285-325. https://doi.org/10.1007/s40273014-0242-y.

19. KPMG LLP. The global economic impact of anti-microbial resistance. 2014. www.kpmg.com/uk/economicoutlook. Accessed 1 Dec 2018.

20. Taylor J, Hafner M, Yerushalmi E, Smith R, Bellasio J, Vardavas R, et al. Estimating the economic costs of antimicrobial resistance: model and results: RAND Europe; 2014. https://www.rand.org/pubs/research_reports/ RR911.html. Accessed 30 Jan 2020

21. de Kraker MEA, Stewardson AJ, Harbarth S. Will 10 million people die a year due to antimicrobial resistance by 2050? PLoS Med. 2016;13:e1002184. https://doi.org/10.1371/journal.pmed.1002184.

22. Howard D, Cordell R, McGowan JE, Packard RM, Scott RD, Solomon SL, et al. Measuring the economic costs of antimicrobial resistance in hospital settings: summary of the Centers for Disease Control and Prevention-Emory workshop. Clin Infect Dis. 2001;33:1573-8. https://doi.org/10.1086/323758.

23. Kaier K, Heister T. Appropriate analysis of the additional costs of antibiotic resistance: the impact of different biases. Value Health. 2016;19:A366-7. https://doi.org/10.1016/j.jval.2016.09.118.

24. Spieker A, Roy J, Mitra N. Analyzing medical costs with time-dependent treatment: the nested g-formula. Health Econ. 2018;27:1063-73. https://doi org/10.1002/hec.3651.

25. Pouwels KB, Vansteelandt S, Batra R, Edgeworth JD, Smieszek T, Robotham $\mathrm{JV}$. Intensive care unit (ICU)-acquired bacteraemia and ICU mortality and discharge: addressing time-varying confounding using appropriate methodology. J Hosp Infect. 2018;99:42-7. https://doi.org/10.1016/J.JHIN 2017.11.011

26. Gregori D, Petrinco M, Bo S, Desideri A, Merletti F, Pagano E. Regression models for analyzing costs and their determinants in health care: an introductory review. Int J Qual Health Care. 2011;23:331-41. https://doi.org/ 10.1093/intqhc/mzr010.

27. Chisholm D, Stanciole AE, Tan Torres Edejer T, Evans DB. Economic impact of disease and injury: counting what matters. BMJ. 2010;340:c924. https:// doi.org/10.1136/bmj.c924.

28. Sandmann FG, Robotham JV, Deeny SR, Edmunds WJ, Jit M. Estimating the opportunity costs of bed-days. Health Econ. 2018;27:592-605.

29. Naylor NR, Pouwels KB, Hope R, Green N, Henderson KL, Knight GM, et al. The health and cost burden of antibiotic resistant and susceptible Escherichia coli bacteraemia in the English hospital setting: A national retrospective cohort study. PLoS One. 2019;14:e0221944. https://doi.org/10. 1371/journal.pone.0221944.

30. Molton JS, Tambyah PA, Ang BSP, Ling ML, Fisher DA. The global spread of healthcare-associated multidrug-resistant bacteria: a perspective from Asia. Clin Infect Dis. 2013:56:1310-8. https://doi.org/10.1093/cid/cit020.

31. Alvarez-Uria G, Gandra S, Mandal S, Laxminarayan R. Global forecast of antimicrobial resistance in invasive isolates of Escherichia coli and Klebsiella pneumoniae. Int J Infect Dis. 2018;68:50-3. https://doi.org/10. 1016/j.ijid.2018.01.011.

32. de Kraker MEA, Davey PG, Grundmann H, on behalf of the BURDEN study group. Mortality and hospital stay associated with resistant Staphylococcus aureus and Escherichia coli bacteremia: estimating the burden of antibiotic resistance in Europe. PLoS Med. 2011;8:e1001104. https://doi.org/10.1371/ journal.pmed.1001104.

33. Reynolds CA, Finkelstein JA, Ray GT, Moore MR, Huang SS. Attributable healthcare utilization and cost of pneumonia due to drug-resistant streptococcus pneumonia: a cost analysis. Antimicrob Resist Infect Control. 2014;3:16. https://doi.org/10.1186/2047-2994-3-16.

34. Teillant A, Gandra S, Barter D, Morgan DJ, Laxminarayan R. Potential burden of antibiotic resistance on surgery and cancer chemotherapy antibiotic prophylaxis in the USA: a literature review and modelling study. Lancet Infect Dis. 2015;15:1429-37. https://doi.org/10.1016/S14733099(15)00270-4.

35. Alsan M, Schoemaker L, Eggleston K, Kammili N, Kolli P, Bhattacharya J. Out-of-pocket health expenditures and antimicrobial resistance in low-income and middle-income countries: an economic analysis. Lancet Infect Dis. 2015;15:1203-10. https://doi.org/10.1016/S14733099(15)00149-8.
36. Coast J, Smith RD, Millar MR. An economic perspective on policy to reduce antimicrobial resistance. Soc Sci Med. 1998;46:29-38. https://doi.org/10. 1016/S0277-9536(97)00132-9.

37. Phelps CE. Bug/drug resistance. Sometimes less is more. Med Care. 1989:27: 194-203.

38. de Vries LM, van Baal PHM, Brouwer WBF. Future costs in cost-effectiveness analyses: past, present, future. Pharmacoeconomics. 2019;37:119-30. https:// doi.org/10.1007/s40273-018-0749-8.

39. Smith RD, Yago M, Millar M, Coast J. Assessing the macroeconomic impact of a healthcare problem: the application of computable general equilibrium analysis to antimicrobial resistance. J Health Econ. 2005;24:1055-75. https:// doi.org/10.1016/J.JHEALECO.2005.02.003.

40. Howard DH. Resistance-induced antibiotic substitution. Health Econ. 2004; 13:585-95. https://doi.org/10.1002/hec.856.

41. Le Doare K, O'Driscoll M, Turner K, Seedat F, Russell NJ, Seale AC, et al. Intrapartum antibiotic chemoprophylaxis policies for the prevention of group B streptococcal disease worldwide: systematic review. Clin Infect Dis. 2017;65(Suppl_2):S143-51. https://doi.org/10. 1093/cid/cix654.

42. Bratzler DW, Dellinger EP, Olsen KM, Perl TM, Auwaerter PG, Bolon MK, et al. Clinical practice guidelines for antimicrobial prophylaxis in surgery. Surg Infect. 2013;14:73-156. https://doi.org/10.1089/sur.2013.9999.

43. Hübner C, Hübner N-O, Hopert K, Maletzki S, Flessa S. Analysis of MRSAattributed costs of hospitalized patients in Germany. Eur J Clin Microbiol Infect Dis. 2014;33:1817-22. https://doi.org/10.1007/s10096-014-2131-x.

44. Rudholm N. Economic implications of antibiotic resistance in a global economy. J Health Econ. 2002;21:1071-83.

45. Chen $\mathrm{H}-\mathrm{H}$, Stringer A, Eguale T, Rao GG, Ozawa S. Impact of antibiotic resistance on treatment of pneumococcal disease in Ethiopia: an agentbased modeling simulation. Am J Trop Med Hyg. 2019;101:1042-53. https:// doi.org/10.4269/ajtmh.18-0930.

46. Chesson HW, Kirkcaldy RD, Gift TL, Owusu-Edusei K, Weinstock HS. An illustration of the potential health and economic benefits of combating antibiotic-resistant gonorrhea. Sex Transm Dis. 2018;45:250-3. https://doi. org/10.1097/OLQ.0000000000000725.

47. Elbasha EH. Deadweight loss of bacterial resistance due to overtreatment. Health Econ. 2003;12:125-38. https://doi.org/10.1002/hec.702.

48. Johnston KJ, Thorpe KE, Jacob JT, Murphy DJ. The incremental cost of infections associated with multidrug-resistant organisms in the inpatient hospital setting - a national estimate. Health Serv Res. 2019;54:782-92. https://doi.org/10.1111/1475-6773.13135.

49. Lee BY, Singh A, David MZ, Bartsch SM, Slayton RB, Huang SS, et al. The economic burden of community-associated methicillin-resistant Staphylococcus aureus (CA-MRSA). Clin Microbiol Infect. 2013;19:528-36. https://doi.org/10.1111/j.1469-0691.2012.03914.x.

50. Michaelidis Cl, Fine MJ, Lin CJ, Linder JA, Nowalk MP, Shields RK, et al. The hidden societal cost of antibiotic resistance per antibiotic prescribed in the United States: an exploratory analysis. BMC Infect Dis. 2016;16:655. https:// doi.org/10.1186/s12879-016-1990-4

51. Phodha T, Riewpaiboon A, Malathum K, Coyte PC. Excess annual economic burdens from nosocomial infections caused by multi-drug resistant bacteria in Thailand. Expert Rev Pharmacoecon Outcomes Res. 2019;19:305-12. https://doi.org/10.1080/14737167.2019.1537123.

52. Shrestha P, Cooper BS, Coast J, Oppong R, Do Thi Thuy N, Phodha T, et al. Enumerating the economic cost of antimicrobial resistance per antibiotic consumed to inform the evaluation of interventions affecting their use. Antimicrob Resist Infect Control. 2018;7:98. https://doi.org/10.1186/s13756018-0384-3

53. Thorpe $K E_{\text {, Joski }} \mathrm{P}$, Johnston KJ. Antibiotic-resistant infection treatment costs have doubled since 2002, now exceeding $\$ 2$ billion annually. Health Aff. 2018;37:662-9. https://doi.org/10.1377/hlthaff.2017.1153.

54. Tillekeratne LG, Bodinayake C, Nagahawatte A, Kurukulasooriya R, Orlando LA, Simmons RA, et al. Use of clinical algorithms and rapid influenza testing to manage influenza-like illness: a cost-effectiveness analysis in Sri Lanka. BMJ Glob Health. 2019;4:e001291. https://doi.org/10.1136/bmjgh-2018001291.

55. Touat M, Opatowski M, Brun-Buisson C, Cosker K, Guillemot D, Salomon J, et al. A payer perspective of the hospital inpatient additional care costs of antimicrobial resistance in France: a matched case-control study. Appl Health Econ Health Policy. 2019;17:381-9. https://doi.org/10.1007/s40258018-0451-1. 
56. U.S. Congress, Office of Technology Assessment. Impacts of AntibioticResistant Bacteria, OTA-H-629. Washington, DC: U.S. Government Printing Office; 1995. https://ota.fas.org/reports/9503.pdf.

57. Zhen X, Li Y, Chen Y, Dong P, Liu S, Dong H. Effect of multiple drug resistance on total medical costs among patients with intra-abdominal infections in China. PLoS One. 2018;13:e0193977. https://doi.org/10.1371/ journal.pone.0193977.

58. Högberg LD, Muller A, Zorzet A, Monnet DL, Cars O. Antibiotic use worldwide. Lancet Infect Dis. 2014;14:1179-80. https://doi.org/10.1016/ S1473-3099(14)70987-9.

59. Pouwels KB, Chatterjee A, Cooper BS, Robotham JV. Antibiotic resistance, stewardship, and consumption. Lancet Planet Health. 2019;3:e66. https://doi. org/10.1016/S2542-5196(18)30283-3.

60. Asche C, McAdam-Marx C, Seal B, Crookston B, Mullins CD. Treatment costs associated with community-acquired pneumonia by community level of antimicrobial resistance. J Antimicrob Chemother. 2008;61:1162-8. https:// doi.org/10.1093/jac/dkn073.

61. Chesson H, Owusu-Edusei K, Kirkcaldy RD, Gift TL, Weinstock HS. P5.096 Estimating the potential economic impact of antimicrobial resistance in Neisseria gonorrhoeae in the United States. Sex Transm Infect. 2013;89(Suppl 1):A365. https://doi.org/10.1136/sextrans-2013-051184.1140.

62. Roy K, Wang SA, Meltzer MI. Optimizing treatment of antimicrobial-resistant Neisseria gonorrhoeae. Emerg Infect Dis. 2005;11:1265-73. https:/doi.org/ 10.3201/eid1108.050157.

63. Elliott RA, Weatherly HLA, Hawkins NS, Cranny G, Chambers D, Myers L, et al. An economic model for the prevention of MRSA infections after surgery: non-glycopeptide or glycopeptide antibiotic prophylaxis? Eur J Health Econ. 2010;11:57-66. https://doi.org/10.1007/s10198-009-0175-0.

64. Ruiz-Ramos J, Frasquet J, Romá E, Poveda-Andres JL, Salavert-Leti M, Castellanos A, et al. Cost-effectiveness analysis of implementing an antimicrobial stewardship program in critical care units. J Med Econ. 2017 20:652-9. https://doi.org/10.1080/13696998.2017.1311903.

65. Oppong R, Smith RD, Little P, Verheij T, Butler CC, Goossens H, et al. Cost effectiveness of amoxicillin for lower respiratory tract infections in primary care: an economic evaluation accounting for the cost of antimicrobial resistance. Br J Gen Pract. 2016;66:e633-9. https://doi.org/10.3399/ bjgp16X686533.

66. Kaier K, Frank U. Measuring the externality of antibacterial use from promoting antimicrobial resistance. Pharmacoeconomics. 2010;28:1123-8. https://doi.org/10.2165/11535640-000000000-00000.

67. Kaier K. Economic implications of the dynamic relationship between antibiotic use and hospital-acquired infections. Value Health. 2012;15:87-93. https://doi.org/10.1016/J.JVAL.2011.09.005.

68. Kaier K. Economic modeling of the persistence of antimicrobial resistance. Nat Resour Model. 2012;25:388-402. https://doi.org/10.1111/j.1939-7445. 2011.00114.x.

69. Pouwels KB, Muller-Pebody B, Smieszek T, Hopkins S, Robotham JV. Selection and co-selection of antibiotic resistances among Escherichia coli by antibiotic use in primary care: an ecological analysis. PLoS One. 2019;14 e0218134. https://doi.org/10.1371/journal.pone.0218134.

70. Pouwels KB, Freeman R, Muller-Pebody B, Rooney G, Henderson KL Robotham JV, et al. Association between use of different antibiotics and trimethoprim resistance: going beyond the obvious crude association. J Antimicrob Chemother. 2018;73:1700-7. https://doi.org/10.1093/jac/dky031.

71. Pouwels KB, Butler CC, Robotham JV. Comment on "The distribution of antibiotic use and its association with antibiotic resistance.". eLife. 2019;8. https://doi.org/10.7554/eLife.46561.

72. Coast J, Smith R, Karcher A-M, Wilton P, Millar M. Superbugs II: how should economic evaluation be conducted for interventions which aim to contain antimicrobial resistance? Health Econ. 2002;11:637-47. https://doi.org/10. 1002/hec.693

73. Livermore DM. The 2018 Garrod lecture: preparing for the black swans of resistance. J Antimicrob Chemother. 2018;73:2907-15. https://doi.org/10. 1093/jac/dky265.

74. Goossens H, Ferech M, Vander Stichele R, Elseviers M. ESAC project group. Outpatient antibiotic use in Europe and association with resistance: a crossnational database study. Lancet. 2005;365:579-87. https://doi.org/10.1016/ S0140-6736(05)17907-0.

75. Lehtinen S, Blanquart F, Croucher NJ, Turner P, Lipsitch M, Fraser C. Evolution of antibiotic resistance is linked to any genetic mechanism affecting bacterial duration of carriage. Proc Natl Acad Sci U S A. 2017;114: 1075-80. https://doi.org/10.1073/pnas.1617849114.

76. Davies NG, Flasche S, Jit M, Atkins KE. Within-host dynamics shape antibiotic resistance in commensal bacteria. Nat Ecol Evol. 2019:3:440-9. https://doi. org/10.1038/s41559-018-0786-x

77. López-Lozano J-M, Lawes T, Nebot C, Beyaert A, Bertrand X, Hocquet D, et al. A nonlinear time-series analysis approach to identify thresholds in associations between population antibiotic use and rates of resistance. Nat Microbiol. 2019;4:1160-72. https://doi.org/10.1038/s41564-019-0410-0.

78. Jansen JP, Kumar R, Carmeli Y. Cost-effectiveness evaluation of ertapenem versus piperacillin/tazobactam in the treatment of complicated intraabdominal infections accounting for antibiotic resistance. Value Health. 2009;12:234-44 https://www.sciencedirect.com/science/article/pii/S10983 01510607000 . Accessed 26 Dec 2018.

79. Haeussler K, van den Hout A, Baio G. A dynamic Bayesian Markov model for health economic evaluations of interventions in infectious disease. BMC Med Res Methodol. 2018;18:82. https://doi.org/10.1186/s12874-018-0541-7.

80. Brown G, Layton DF. Resistance economics: social cost and the evolution of antibiotic resistance. Environ Dev Econ. 1996;1:349-55. https://doi.org/10. 1017/S1355770X0000067X.

81. Andersson DI, Hughes D. Antibiotic resistance and its cost: is it possible to reverse resistance? Nat Rev Microbiol. 2010;8:260-71. https://doi.org/10. 1038/nrmicro2319.

82. Greenhalgh T, Thorne S, Malterud K. Time to challenge the spurious hierarchy of systematic over narrative reviews? Eur J Clin Investig. 2018;48 e12931. https://doi.org/10.1111/eci.12931.

\section{Publisher's Note}

Springer Nature remains neutral with regard to jurisdictional claims in published maps and institutional affiliations.

Ready to submit your research? Choose BMC and benefit from:

- fast, convenient online submission

- thorough peer review by experienced researchers in your field

- rapid publication on acceptance

- support for research data, including large and complex data types

- gold Open Access which fosters wider collaboration and increased citations

- maximum visibility for your research: over $100 \mathrm{M}$ website views per year

At $\mathrm{BMC}$, research is always in progress.

Learn more biomedcentral.com/submissions 